\title{
Effects of herbs and spice on health status of tilapia (Oreochromis mossambicus) challenged with Streptococcus iniae
}

\author{
Nejdet Gültepe ${ }^{1}$, Soner Bilen², Sevdan Y1lmaz ${ }^{3}$, Derya Güroy ${ }^{4}$, Seyit Aydın ${ }^{1}$ \\ ${ }^{1}$ Kastamonu University, Faculty of Engineering and Architecture, \\ Department of Genetics and Bioengineering, Turkey \\ ${ }^{2}$ Kastamonu University, Faculty of Fisheries, Department of Basic Sciences, Turkey \\ ${ }^{3}$ Canakkale Onsekiz Mart University, Faculty of Marine Sciences and Technology, \\ Department of Aquaculture, Turkey \\ ${ }^{4}$ Yalova University, Armutlu Vocational School, Department of Aquaculture, Turkey
}

Received August 16, 2013

Accepted March 26, 2014

\begin{abstract}
Effects of different herbal extracts on the growth and immune defense of fish were researched in the last decade. The aim of this study was to determine the dietary effects of thyme (Thymus vulgaris), rosemary (Rosmarinus officinalis) and fenugreek (Trigonella foenum graecum) as a feed additive on haematology, innate immune response, and disease resistance of tilapia (Oreochromis mossambicus). In total 228 healthy fish tilapia were divided into four groups (57 fish in one group) and fed diets supplemented with thyme, rosemary and fenugreek at levels of $1 \%$, respectively; fish in the control group were fed diet without any spices. Fish were fed ad libitum three times a day for 45 days. All fish of the experimental groups significantly $(P<0.05)$ enhanced phagocytic activity, haematocrit, white blood cell, red blood cell, neutrophil and monocyte counts in blood. Significant $(P<0.05)$ increase of plasma myeloperoxidase and lysozyme activity was found in fish receiving a feed supplemented with fenugreek after 30 days. Respiratory burst activity was non-significantly $(P>0.05)$ changed during the whole experiment. After 45 days of feeding, fish were injected intraperitoneally with $100 \mu \mathrm{l}$ of Streptococcus iniae $\left(8 \times 10^{8}\right.$ colony forming unit). The cumulative mortality was $22 \%, 27 \%$ and $31 \%$ in fish receiving diets supplemented with $1 \%$ thyme, rosemary and fenugreek, respectively, compared to $61 \%$ mortality in the control group. The results indicate that all three supplements used improved the haematological status, non-specific immune response and disease resistance of tilapia against S. iniae; this is the first similar study.
\end{abstract}

Thymus vulgaris, Rosmarinus officinalis, Trigonella foenum graecum, immunostimulant

Streptococcal disease is the cause of significant economic losses in tilapia culture industry, and it is mainly controlled by antibiotics. Previous studies showed that herbs or spices such as Rosmarinus officinalis (Zilberg et al. 2010) and Cuminum cyminum (Y $11 \mathrm{maz}$ et al. 2012) are successfully used instead of antibiotics in tilapia culture. Thyme has a strong antimicrobial and antioxidant activity due to its very high contents of thymol, p-cymene, carvacrol, eugenol, and 4-allylphenol. The carnosic acid and rosmarinic acids are the main chemical constituents of rosemary, and they have a particularly high antioxidant activity. Fenugreek is rich in flavonoids (such as apigenin, kaempferol and quercetin) and saponins (such as diosgenin and yamogenin) that protect cells from oxidative damage and have immunostimulatory properties. The antioxidant effects of many components have been reported to activate the fish immune system. Thyme, rosemary and fenugreek could enhance the immune systems of different animal species, such as broiler chickens and rats. Rosemary and fenugreek also increase disease resistance against Streptococcus agalactiae, S. iniae and Aeromonas hydrophila in Oreochromis sp. (Zilberg et al. 2010) and $O$. niloticus (Mostafa et al. 2009), respectively.

The aim of the present study was to investigate the effects of thyme, rosemary and

Address for correspondence:

Nejdet Gültepe

Kastamonu University

Faculty of Engineering and Architecture

Department of Genetics and Bioengineering

37200, Kastamonu, Turkey

Phone: +905326334769

E-mail: nejdetgultepe@yahoo.com

http://actavet.vfu.cz/ 
fenugreek supplementation diet on the haematology, innate immune response and disease resistance of tilapia against $S$. iniae.

\section{Materials and Methods}

\section{Experimental design}

The experiment was performed on 228 healthy tilapia fish (Oreochromis mossambicus) with the mean weight of $13.0 \pm 0.10 \mathrm{~g}$. The fish were produced at Canakkale Onsekiz Mart University, Faculty of Fisheries, Department of Aquaculture in Turkey. Before the experiment started, the fish were fed a diet containing 34\% protein and $10 \%$ fat. After two weeks, the fish were randomly divided into 12 cylindro-conical fibreglass tanks of 1401 with 19 fish per tank and equipped with the recirculation system. Water was exchanged daily corresponding to about $10 \%$ of total volume. During the experiment, water properties (mean $\pm \mathrm{SE}$ ) were measured daily with the following values obtained: temperature $28.4 \pm 0.6^{\circ} \mathrm{C}, \mathrm{pH} 7.8 \pm 0.5$, dissolved oxygen $7.04 \pm 0.9 \mathrm{mg} \cdot \mathrm{l}^{-1}$, total ammonia 0.09 $\pm 0.01 \mathrm{mg} \cdot l^{-1}$, nitrate $1.1 \pm 0.1 \mathrm{mg} \cdot l^{-1}$, nitrite $0.03 \pm 0.01 \mathrm{mg} \cdot \cdot^{-1}$ and conductivity $554 \pm 16 \mathrm{uS}$.

Four experimental diets were formulated for the fish. Three of them contained thyme (group T), rosemary (group R) and fenugreek (group F) at a 1\% concentration (Table 1); the control group was without supplementation with herbs or spices. Thyme (Thymus vulgaris), rosemary (Rosmarinus officinalis) and fenugreek (Trigonella foenum graecum) powders were obtained from a local market (Harman Business, Turkey). The feed was produced with a standard pelleting machine. Fish were fed ad libitum $\times 3$ a day at 9:00, 13:00 and 17:00 h for 45 days. The experiment was performed in accordance with the guidelines for fish research from the animal ethics committees at Canakkale University, Turkey. Blood samples of randomly selected 6 fish per group were collected from the caudal vein using a fitted 5-ml vacutainer on days $0,15,30$, and 45 . The sample of blood (EDTA) was taken for haematological and immunological analysis.

Table 1. Formulation of experimental diet for fish tilapia.

\begin{tabular}{lc}
\hline Ingredients & Concentration $(\mathrm{g} / 100 \mathrm{~g})$ \\
\hline Fish meal $^{\mathrm{a}}$ & 30 \\
Soybean meal $^{\mathrm{a}}$ & 33 \\
Wheat flour $^{\mathrm{a}}$ & 16.2 \\
Fish oil $^{\mathrm{a}}$ & 6.5 \\
Vitamin-mineral mix $^{\mathrm{b}, \mathrm{c}}$ & 4 \\
Starch $^{\mathrm{d}}$ & $10.3-9.3$ \\
$*$ Herbs and spice & 1 \\
\hline
\end{tabular}

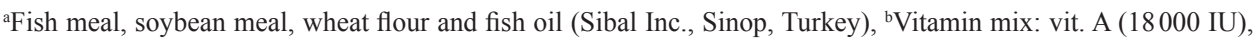
vit $\mathrm{D}_{3}(2500 \mathrm{IU})$, vit. $\mathrm{E}\left(250 \mathrm{mg} \cdot \mathrm{kg}^{-1}\right)$, vit. $\mathrm{K}_{3}\left(12 \mathrm{mg} \cdot \mathrm{kg}^{-1}\right)$, vit. $\mathrm{B}_{1}(25 \mathrm{mg})$, vit. $\mathrm{B}_{2}(50 \mathrm{mg})$, vit. $\mathrm{B}_{3}(270 \mathrm{mg})$, vit. $B_{6}(20 \mathrm{mg})$, vit. $B_{12}(0.06 \mathrm{mg})$, vit. C (200 mg), Folic acid (10 mg), Calcium d-pantothenate (50 mg), Biotin (1 $\mathrm{mg}$ ), Inositol (120 mg), Choline chloride (2000 mg), ${ }^{\circ}$ Mineral mix: Fe (75.3 mg), Cu (12.2 mg), Mn (206 mg), $\mathrm{Zn}(85 \mathrm{mg})$, I (3 mg), Se (0.350 mg), Co (1 mg), ${ }^{\mathrm{d}}$ Wheat starch (Kenton, Ankara, Turkey), ${ }^{\mathrm{e}}$ Thyme, rosemary and fenugreek (Harman Business, Istanbul, Turkey). *Substituting the herbs and spice for $1 \%$ starch.

\section{Haematology}

Aqueous solution of heparin sodium salt at $0.01 \mathrm{ml}$ per $1 \mathrm{ml}$ blood was used to stabilize the blood samples. Red blood cells $\left(\mathrm{RBC}, 10^{6} \mathrm{~mm}^{3}\right)$, white blood cells $\left(\mathrm{WBC}, 10^{3} \mathrm{~mm}^{3}\right)$, haematocrit (PCV, \%) and haemoglobin $(\mathrm{Hb}, \mathrm{g} /$ dl) were determined using standard methods according to Foop-Bayat et al. (2013) and Zusková et al. (2013). Differential leukocytes were examined in May-Grunwald-Giemsa-stained peripheral blood smears; each slide was examined under oil-immersion at $\times 100$ and for each slide, 100 leukocytes were identified as lymphocytes, neutrophils or monocytes.

\section{Immunology}

Phagocytic activity was estimated using the modified method by Siwicki et al. (1994). Phagocytic activity (PA) was calculated as:

$\mathrm{PA}=($ number of phagocytic cells/number of total cells $) \times 100$.

The respiratory burst activity of the neutrophils and monocytes was quantified by the reduction nitroblue tetrazolium (NBT) to formazan as a measurement of production of oxygen radicals. Plasma lysozyme was assessed using the turbidometric assay; total myeloperoxidase activity in blood plasma was measured according to Gültepe et al. (2014). 

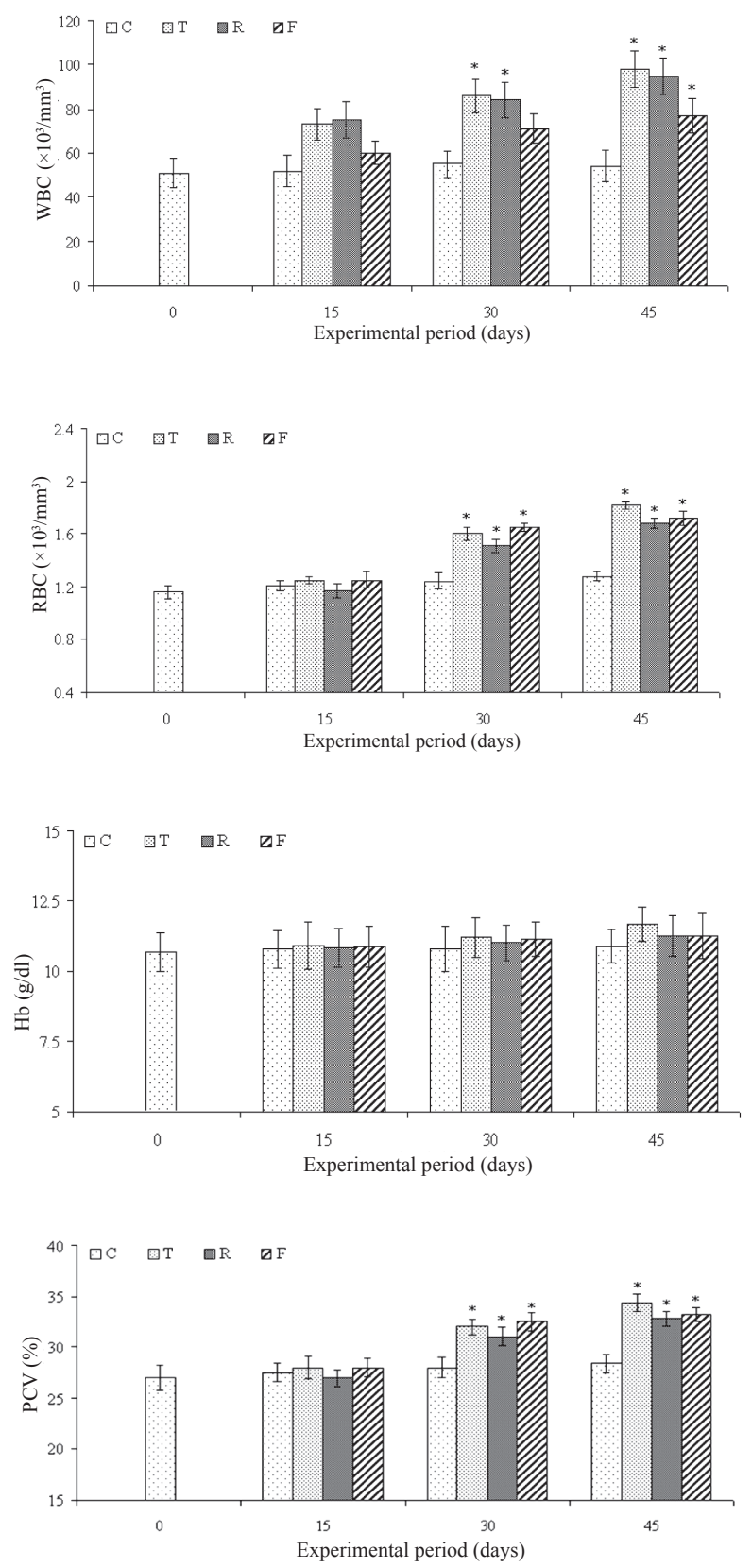

Fig. 1. Changes in the haematological indicators of tilapia fed diets supplemented with thyme, rosemary and fenugreek.

Groups: C - control without supplementation, $\mathrm{T}$ - supplemented with thyme, $\mathrm{R}$ - supplemented with rosemary, $\mathrm{F}$ - supplemented with fenugreek. Blood indicators: WBC - white blood cells, $\mathrm{RBC}-$ red blood cells, $\mathrm{Hb}-$ haemoglobin, PCV - haematocrit. Values are expressed as mean \pm SEM $(n=6) . ~ *$ Significantly different from controls $(P<0.05)$. 

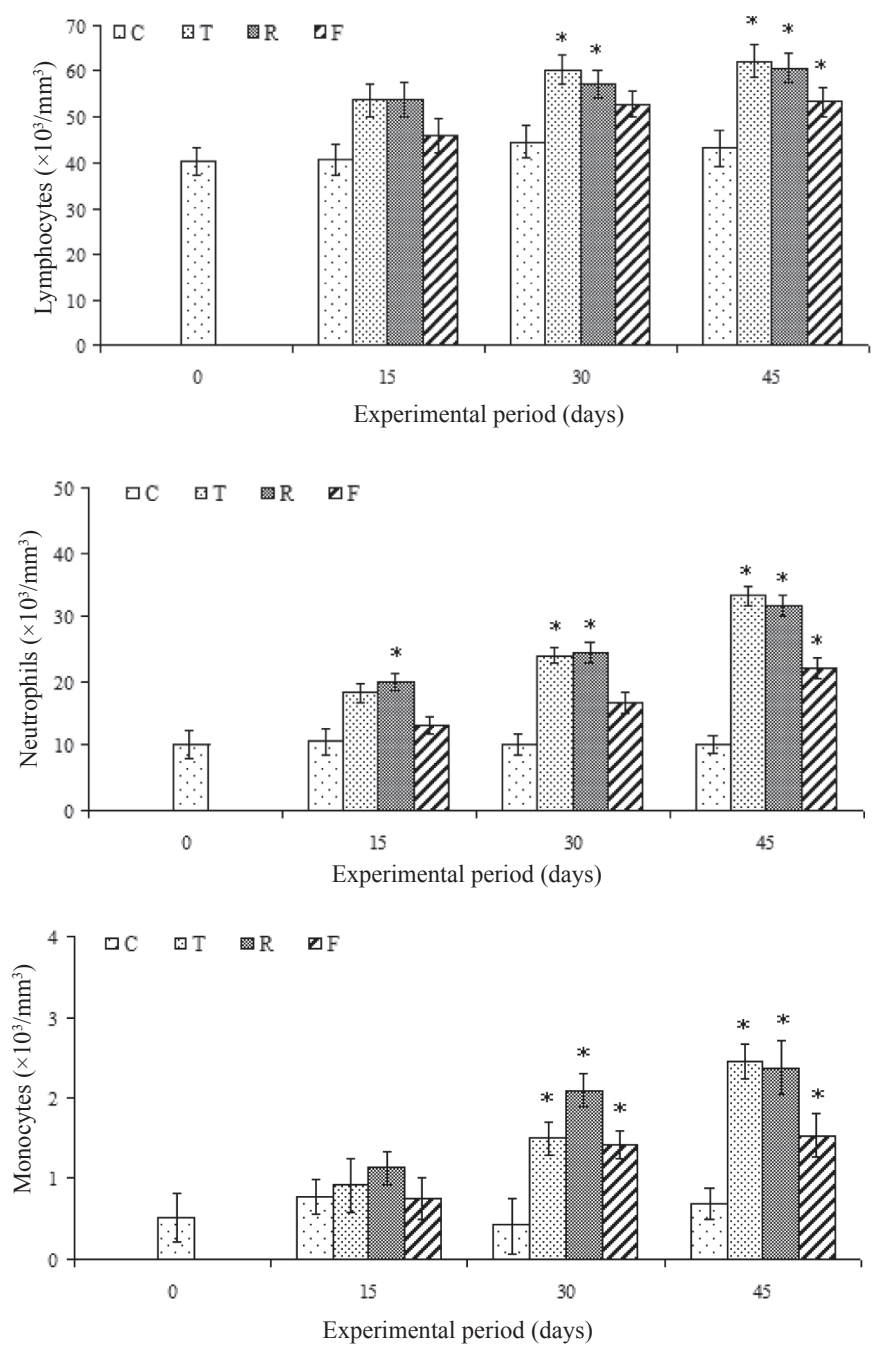

Fig. 2. Changes in the white blood cells of tilapia fed diets supplemented with thyme, rosemary and fenugreek.

Groups: C - control without supplementation, $\mathrm{T}$ - supplemented with thyme, $\mathrm{R}$ - supplemented with rosemary, $\mathrm{F}$ - supplemented with fenugreek. Values are expressed as mean \pm SEM $(\mathrm{n}=6)$. *Significantly different from controls $(P<0.05)$.

\section{Experimental infection}

The bacterium (Streptococcus iniae) was previously isolated from diseased tilapia. The challenge experiment was performed according to Y1lmaz et al. (2012). After 45 days of feeding, fish were injected intraperitoneally with $100 \mu \mathrm{l} \mathrm{S}$. iniae $\left(8 \times 10^{8}\right.$ colony forming unit) The cumulative mortality was recorded at $24,48,72,86$, and $96 \mathrm{~h}$.

\section{Statistics}

The data of haematological and immunological indicators in groups of fish supplemented with different herbs or spice were compared to the control diet group with $t$-test using SPSS 17.0 packaged software. Mortality in each group supplemented with herbs or spice was compared to the control group using Chi-square test (SPSS 17.0) $(P<0.05)$. 

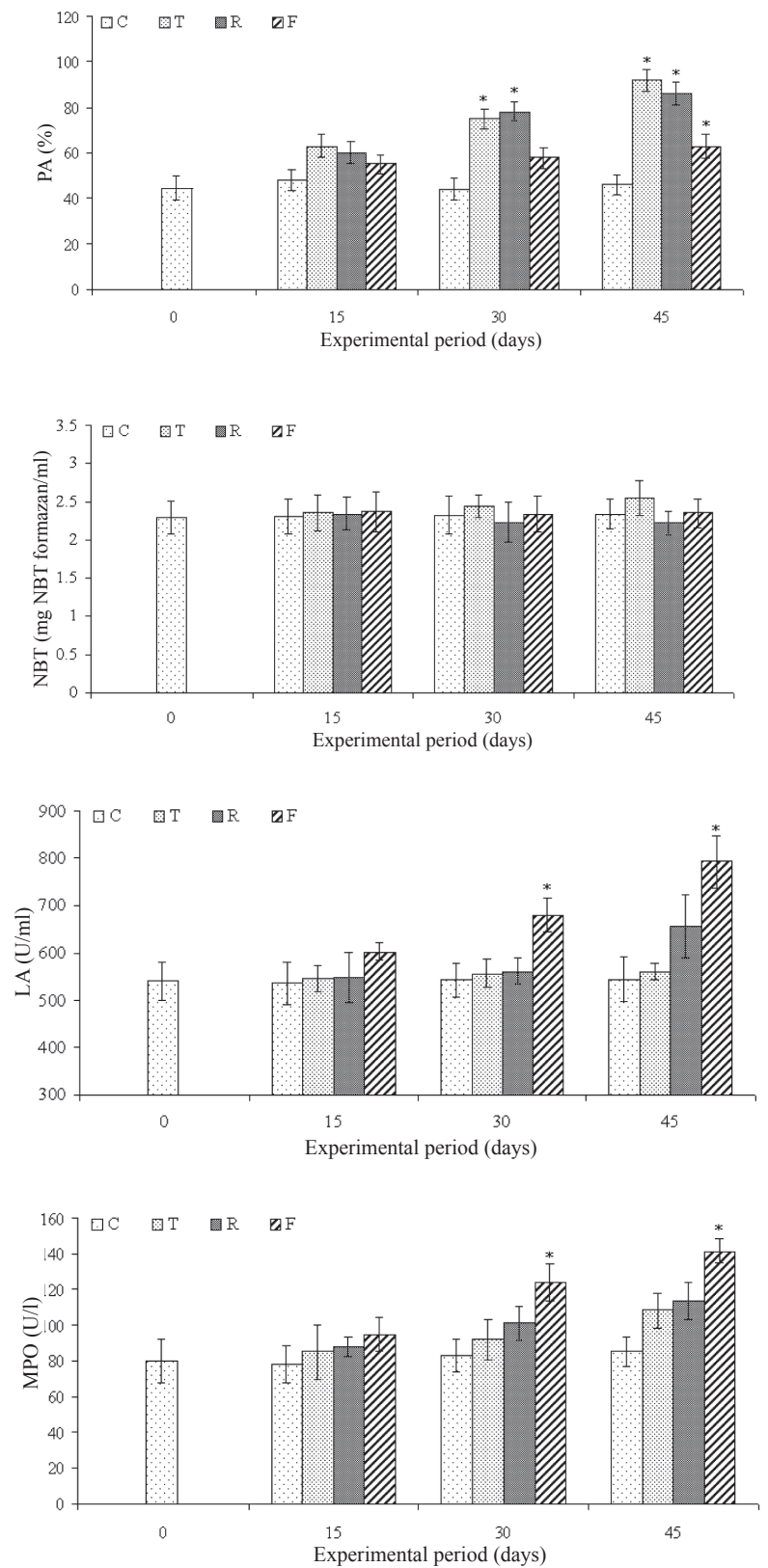

Fig. 3. Changes in the immunological properties of tilapia fed diets supplemented with thyme, rosemary and fenugreek.

Groups: $\mathrm{C}$ - control without supplementation, $\mathrm{T}$ - supplemented with thyme, $\mathrm{R}$ - supplemented with rosemary, $\mathrm{F}$ - supplemented with fenugreek. PA - phagocytic activity, NBT - reduction nitroblue tetrazolium, LA - lysozyme activity, MPO - myeloperoxidase activity. Values are expressed as mean $\pm \operatorname{SEM}(\mathrm{n}=6)$. *Significantly different from controls $(P<0.05)$. 


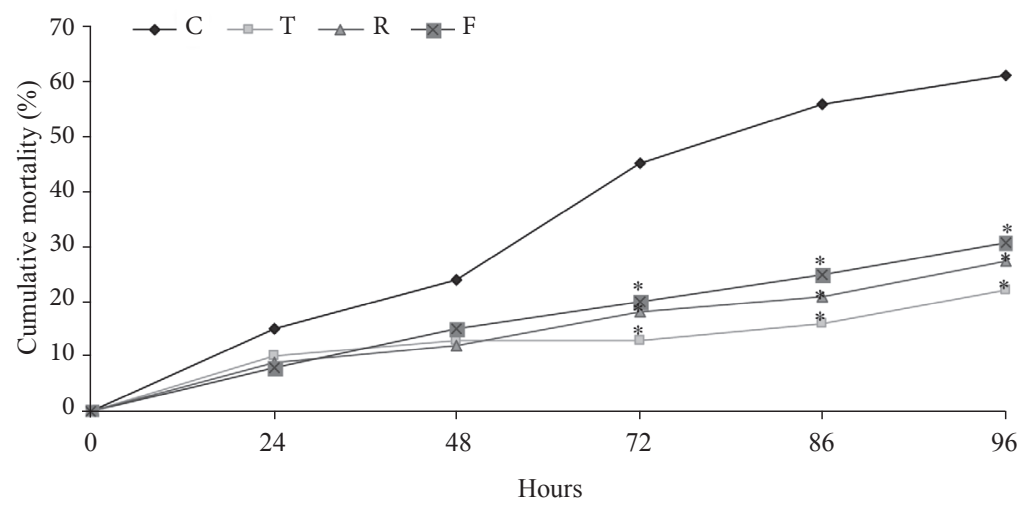

Fig. 4. Cumulative mortality of tilapia $(n=30)$ fed diets supplemented with thyme, rosemary and fenugreek, and challenged with the bacterium Streptococcus iniae for $96 \mathrm{~h}$.

Groups: $\mathrm{C}$ - control without supplementation, $\mathrm{T}$ - supplemented with thyme, $\mathrm{R}$ - supplemented with rosemary, $\mathrm{F}$ - supplemented with fenugreek. *Significantly different from controls $(P<0.05)$.

\section{Results}

$\mathrm{RBC}$ and $\mathrm{PCV}$ concentrations in groups $\mathrm{T}, \mathrm{R}$ and $\mathrm{F}$, and $\mathrm{WBC}$ counts in group $\mathrm{F}$ are given in Fig. $1(P<0.05)$. Lymphocyte, neutrophil and monocyte percentages (Fig. 2) significantly changed in groups $\mathrm{T}, \mathrm{R}$ and $\mathrm{F}$ when compared to control $(P<0.05)$ on different days, and also eosinophil was not found. Feeding the fish with $1 \%$ of $\mathrm{T}, \mathrm{R}$ and $\mathrm{F}$ groups significantly increased $(P<0.05)$ the phagocytic activity in the blood of the $O$. mossambicus (Fig. 3). The level of respiratory burst activity in all groups was non-significant on days 15,30 and 45 of sampling $(P>0.05)$ (Fig. 3). The lysozyme activity was not significantly enhanced in groups of fish fed the $\mathrm{T}$ and $\mathrm{R}$ diet on all days, compared to control $(P>0.05)$. However, a significant increase of plasma lysozyme activity was found in groups receiving feed containing $\mathrm{F}$ after 30 days (Fig. 3). Myeloperoxidase activity was significantly $(P<0.05)$ increasing only in group $\mathrm{F}$ at day 30 and 45 , compared to the control group (Fig. 3). Cumulative mortality in groups T, R and F was significantly decreased at the end of $96 \mathrm{~h}$ compared to the control group (Fig. 4); it was $22 \%, 27 \%$ and $31 \%$ in fish of groups T, R and F, respectively, at $96 \mathrm{~h}$ of $S$. iniae challenge. However, in fish fed with non-supplemented control diet $(0 \%)$ a maximum mortality of $61 \%$ was found.

\section{Discussion}

In our study, we detected that some haematological indicators (WBC, RBC, PCV, neutrophils and monocyte) in Oreochromis mossambicus fed with diets supplemented with thyme, rosemary and fenugreek, significantly increased compared to control. Previous reports showed that haematological indicators increased in fish that were fed garlic and ginseng (Shelby et al. 2006), and allicin (Nya et al. 2010). Mostafa et al. (2009) reported an increase of $\mathrm{RBC}, \mathrm{PCV}$ and $\mathrm{Hb}$ in $\mathrm{O}$. mossambicus fish after feeding them with fenugreek.

Immune systems can be activated by the immunostimulants in several ways: enhancing the number of phagocytes, activating phagocytes or increasing the synthesis of the involved molecules. In our study, fish fed with thyme, rosemary and fenugreek showed elevated phagocytic activity (especially in case of neutrophils). However, administration 
of herbs and spice did not enhance respiratory burst (NBT) activity. Levels of lysozyme can be increased after supplementation of $O$. niloticus and $O$. mossambicus with herbs such as Astragalus membranaceus, Lonicera japonica (Ardó et al. 2008) and Nyctanthes arbortristis (Kirubakaran et al. 2010). In our study, lysozyme activity was significantly increased only in the diet supplemented with fenugreek. Kirubakaran et al. (2010) reported that herb addition increased the level of myeloperoxidase in O. mossambicus; likewise we have proved in our study.

Previous studies showed that tilapias fed a diet including Cinnamomum verum, Andrographis paniculata (Rattanachaikunsopon and Phumkhachorn 2009), Rosmarinus officinalis (Zilberg et al. 2010) and Cuminum cyminum (Y1lmaz et al. 2012) increased the survival rate against streptococcal challenge. Similarly in our study, we detected reduced mortality in fish of all three groups supplemented with herbs and spice that were challenged with $S$. iniae.

In conclusion, the results of this study indicate that supplementation of fish with thyme, rosemary or fenugreek could improve the haematological and immunological properties and also increase the survival rate after challenge with $S$. iniae. These herbs and spice can be used as immunostimulants to enhance the immune responses and resistance of O. mossambicus.

\section{References}

Ardó L, Yin G, Xu P, Váradi L, Szigeti G, Jeney Z, Jeney G 2008: Chinese herbs (Astragalus membranaceus and Lonicera japonica) and boron enhance the non-specific immune response of Nile tilapia (Oreochromis niloticus) and resistance against Aeromonas hydrophila. Aquaculture 275: 26-33

Foop-Bayat D, Wlasow T, Ziomek E 2013: Haematology of gynogenetic diploids of Siberian sturgeon Acipenser baerii Brandt. Acta Vet Brno 82: 081-085

Gültepe N, Acar Ü, Kesbiç OS, Yılmaz S, Yıldırım Ö, Türker A 2014: Effects of dietary Tribulus terrestris extract supplementation on growth, feed utilization, hematological, immunological and biochemical variables of Nile tilapia Oreochromis niloticus. Isr J Aquac 2014, IJA 66.2014.1024

Kirubakaran CJW, Alexander CP, Michael RD 2010: Enhancement of non-specific immune responses and disease resistance on oral administration of Nyctanthes arbortristis seed extract in Oreochromis mossambicus (Peters). Aquac Res 41: 1630-1639

Mostafa AAZM, Ahmad MH, Mousallamy A, Samir A 2009: Effect of using dried fenugreek seeds as natural feed additives on growth performance, feed utilization, whole-body composition and entropathogenic Aeromonas hydrophila-challinge of monsex Nile tilapia O. niloticus (L) fingerlings. Aust J Bs App Sci 3: 1234-1245

Nya EJ, Dawood Z, Austin B 2010: The garlic component, allicin, prevents disease caused by Aeromonas hydrophila in rainbow trout, Oncorhynchus mykiss (Walbaum). J Fish Dis 33: 293-300

Rattanachaikunsopon P, Phumkhachorn P 2009: Protective effect of clove oil-supplemented fish diets on experimental Lactococcus garvieae infection in tilapia. Biosci Biotech Biochem 73: 2085-2089

Shelby RA, Lim CE, Aksoy M, Delaney MA 2006: Effects of probiotic feed supplements on disease resistance and immune response of young Nile tilapia (Oreochromis niloticus). J App Aquac 18: 23-34

Siwicki AK, Anderson DP, Rumsey GL 1994: Dietary intake of immunostimulants by rainbow trout effects nonspecific immunity and protection against furuncluosis. Vet Immunol Immunopathol 41: 125-139

Y1lmaz S, Ergün S, Türk N 2012: Effects of Cumin-supplemented diets on growth and disease (Streptococcus iniae) resistance of tilapia (Oreochromis mossambicus). Isr J Aquac IJA 64.2012.768

Zilberg D, Tal A, Froyman N, Abutbul S, Dudai N, Goldhirsh AG 2010: Dried leaves of Rosmarinus officinalis as a treatment for streptoccosis in tilapia. J Fish Dis 33: 361-369

Zusková E, Máchová J, Velíšek J, Stará A, Svobodová Z, Kroupová HK 2013. Recovery of rainbow trout (Oncorhynchus mykiss) after subchronic nitrite exposure. Acta Vet Brno 82: 073-079 